OnLine Journal of Biological Sciences 9 (3): 81-85, 2009

ISSN 1608-4217

(C) 2009 Science Publications

\title{
Indications of Potential Toxic/Mutagenic Effects of World Trade Center Dust on Human Lung Cell Cultures
}

\author{
Constantino G. Lambroussis, Barbara D. Soares, Sergio Perez, David Gaipa, Anise L. Elie, \\ Caitlin M. Ament, Fahad T. Rouf, Lotfi M. Bassa and Ann Marie DiLorenzo \\ Department of Biology and Molecular Biology, Montclair State University, Montclair, NJ 07043
}

\begin{abstract}
Problem statement: Respiratory complications have been linked with exposure to dust particulates after the tragedy of September 11th, 2001 at the World Trade Center (WTC) site. Approach: The purpose of these experiments was to investigate the extent of cellular damage resulting from WTC dust exposure. Results: This research project was conducted with human lung fibroblast cells exposed to WTC dust. To determine if cell proliferation levels were affected, cultured cells were exposed to WTC dust at various concentrations in simulated physiological stress environments via decreased serum levels. Results indicated that cell proliferation levels decreased as WTC dust concentrations increased. This pattern persisted regardless of serum level. The serum concentrations used were 10\% Fetal Bovine Serum (FBS), which represented a non-stressed system, with 2.5 and 1\% FBS concentrations used to simulate stressed environments. Assessment for apoptosis, programmed cell death, resulted in higher than baseline levels in cells exposed to WTC dust in both MRC-5 and WI-38 human lung fibroblasts. Conclusion/Recommendations: In summary, results showed that exposure to WTC dust led to decreased cell proliferation and increased apoptosis levels. These findings evidence need for future research regarding mutagenic properties of World Trade Center dust.
\end{abstract}

Key words: WTC, airborne particulates, particles, human lung fibroblast cells, proliferate, apoptose, mutagen, toxin

\section{INTRODUCTION}

On September 11, 2001, a large quantity of dust filled the air following the collapse of the World Trade Center Towers. Once the dust began to settle, it covered a large portion of lower Manhattan. A research team from Rutgers University, directed by Lioy ${ }^{[9]}$, examined various collections of World Trade Center dust to determine its chemical composition. They analyzed samples containing different particle sizes. The larger, heavier particles settled before the lighter smaller particles. The lighter particles remained in the air and floated a greater distance from the World Trade Center (WTC) site than the larger particles. The collection sites for dust analyzed in this study were Market Street, Cherry Street and Cortlandt Street. The samples of WTC dust analyzed contained numerous heavy metals as well as jet fuel hydrocarbons ${ }^{[9]}$. In a study on diesel fuel conducted in Massachusetts, it was found that higher diesel particulate matter levels in an area coincided with increased levels of asthma. This study also suggested that diesel was correlated with increased levels of lung cancer ${ }^{[10]}$. The dust sample used for this study was provided by Lioy $^{[9]}$ and was originally obtained from the hood of a parked vehicle on Market Street. This dust contained the materials rescue workers would have been most likely to have inhaled.

Occupational inhalation of heavy metals is associated with lung cancers ${ }^{[2]}$. Materials within the WTC dust included lead, asbestos, glass, as well as numerous aromatic ring compounds ${ }^{[3]}$. The International Agency for Research on Cancer has categorized certain heavy metals as carcinogens ${ }^{[2]}$. The respiratory system is a direct target of possible environmental carcinogens ${ }^{[5]}$. Lungs respond to inhaled agents in a variety of ways. Inhaled agents may lead to constriction of air passages as well as destruction of lung tissue ${ }^{[3]}$. For example, the inhalation of nickelcontaining substances has been shown to be linked to a rise in Transforming Growth Factor Beta (TGF-B) levels, yielding morphological changes in the lung tissue. These changes to the lung tissue may also result

Corresponding Author: Professor Constantino G. Lambroussis, Department of Biology and Molecular Biology, Montclair State University, Montclair, NJ 07043 Tel: (908)-688-2148 
in respiratory failure ${ }^{[11]}$. Inflammation of the lung tissues as a result of inhaled toxins is also considered to be a lung cancer risk factor ${ }^{[4]}$.

"World Trade Center Cough" first surfaced within $24 \mathrm{~h}$ after the building collapses. Rescue workers assessed during a 6 month period following the incident, presented symptoms which resulted in the diagnosis of Reactive Airway Dysfunction Syndrome (RADS). Symptoms of RADS include wheezing, difficulty breathing, bronchial constriction, reduced lung volume capacity, as well as possible abnormalities in the morphology of cells lining the air passages ${ }^{[3]}$. Lung carcinomas are the leading cause of cancer deaths throughout the world ${ }^{[6]}$. Cancerous cells contain an unstable genome, which may include fragmented DNA. Genomic damage to a cell can be used to indicate risk for inducing cancer in exposed cells ${ }^{[1]}$.

The cell cycle summarizes cell activity from its initial formation to its death. The cell cycle is comprised of the following phases: $G_{1} / G_{0}, S, G_{2}$ and $M$. The progression of the cell cycle is dependent upon signals originating from DNA, cyclins, cyclin dependent kinases and various inhibitors. If DNA is damaged beyond repair and the $G_{0}$ phase is not activated, the cell may undergo apoptosis ${ }^{[8]}$. Changes in a cell's morphology, cytoskeletal structure and DNA damage are indicators of cells which may undergo apoptosis $^{[7]}$. Identifying WTC dust as a potential mutagen/carcinogen may aid in better identification of those who may be at an elevated risk for lung cancer. This may also assist in understanding a potential occupational hazard arising from building demolition.

\section{MATERIALS AND METHODS}

MRC-5 and WI-38 Human Lung Fibroblast Cells were initially grown in Eagle's Minimum Essential Medium (MEM), supplemented with 10\% Fetal Bovine Serum (FBS) in T-25 flasks. Subculturing was consistently performed via scraping, following the formation of a confluent monolayer of cells. All flasks containing cells were incubated at $37^{\circ} \mathrm{C}$ in an environment with $5 \% \quad \mathrm{CO}_{2}$. Sterile conditions were maintained throughout the duration of the project.

Preparation of a stock solution of WTC dust with media was made by measuring out $100 \mathrm{mg}$ of WTC Dust under a fume hood and adding sufficient MEM (with $10 \% \mathrm{FBS}$ ) to bring the overall volume up to $100 \mathrm{~mL}$. This stock solution represents a 1000 ppm concentration of WTC dust. Appropriate dilutions were performed to make $250,125,25,12.5,2.5$ and 1.25 ppm WTC dust solutions. As a control, MEM with $10 \%$ FBS was used. Following the formation of a confluent monolayer in the subcultured flasks, the MRC-5 and WI-38 cells were placed into the wells of a flat bottom 96 well plate and grown in MEM with $10 \%$ FBS until confluent monolayers formed. Upon formation of a confluent monolayer in each well, the MEM with $10 \%$ FBS was removed and specific test media were added. All cells were exposed to the test media for a period of $24 \mathrm{~h}$, incubated at $37^{\circ} \mathrm{C}$ with $5 \% \mathrm{CO}_{2}$ during that time. The proliferation portion of this study was conducted using lower percentages of FBS in the media to simulate the effects of physiological stress on the cells. The lower FBS levels used were $2.5 \%$ and $1 \%$. The proliferation study used only MRC-5 cells. Proliferation assessment utilized the Promega CellTiter 96 Aqueous Non-Radioactive Cell Proliferation Assay (Cat. \#G5421), following Promega technical bulletin \#TB169. Readings at 490nm were taken after incubation. To normalize data, control value was subtracted.

The apoptosis study was performed using both MRC-5 and WI-38 cells. Promega Caspase-Glo 3/7 Assay (Cat. \#G8091), following Promega technical bulletin \#TB323, was used for the assessment of apoptosis. Arrangement within 96-well plates was similar to the proliferation study. However, only $2.5,25$ and $250 \mathrm{ppm}$ concentrations of WTC dust were used following the assessment of the proliferation study. In addition, the same concentrations were used with household dust and gypsum for comparison to WTC dust. Gypsum is a component of dry wall used in most buildings. Household dust was assessed as it is a substance that is normally inhaled on a daily basis and cannot be avoided. Following exposure of $24 \mathrm{~h}$ to test media, luminescence readings were taken. As with the proliferation study, the control value was subtracted to normalize the data.

Particle size analysis was conducted to ensure that particles of each sample were of comparable size. The particle size analysis was conducted using a Mastersizer 2000 unit with a Hydro 2000 MU Unit Accessory by Malvern Instruments. Millipore filtered water was used to take a background measurement before each sample was analyzed. These background measurements were then cancelled out from the household dust, gypsum and World Trade Center dust readings. Analysis of WTC dust and household dust was performed using the Carbon Standard Operating Procedure (SOP). Gypsum was analyzed using the Gypsum SOP.

\section{RESULTS}

Proliferation: Figure 1 shows the corrected data (control subtracted from each experimental condition) 
for all test conditions of the proliferation assay conducted with MRC-5 human lung fibroblast cells. Higher negative absorbance values indicate decreased proliferation.

Apoptosis: Figure 2 shows the apoptosis data normalized against $10 \%$ FBS media + reagent, lacking cells. The empty column on the far left of each graph represents the normalized data. The reading for the column is near 0 with minimal error. Baseline apoptosis levels are represented in the column on the far right of each graph (labeled cells $+10 \%+$ reagent)

Particle size analysis: Figure 3 shows the size analysis obtained from the Mastersizer 2000 with the Hydro 2000 MU Unit Accessory by Malvern Instruments. The tallest peaks represent the highest concentration at the size level.

\section{DISCUSSION}

The proliferation study (Fig. 1) shows that at $12.5 \mathrm{ppm}$ and higher concentrations of WTC dust will definitely inhibit continuation of MRC-5 human lung fibroblast cell proliferation. As ppm of WTC dust

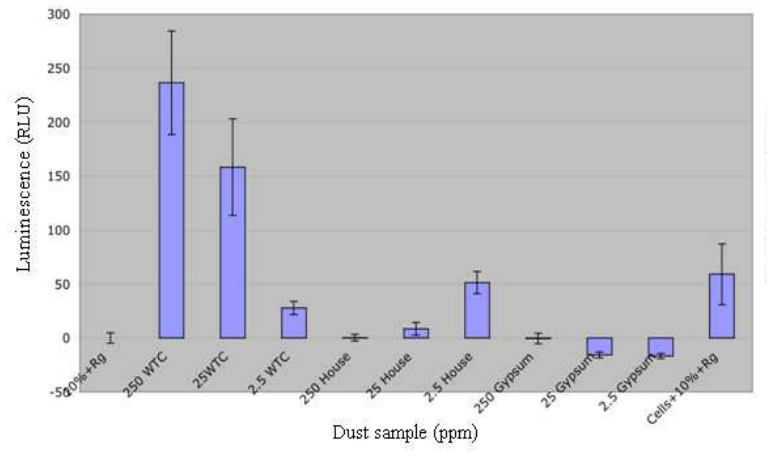

(a)

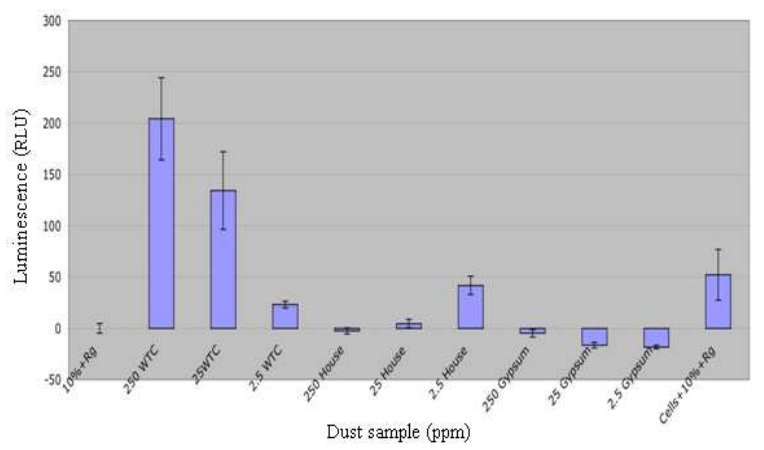

(c) increases, a drop in proliferation is seen in approximately equal levels regardless of FBS concentration in the WTC dust media. 10\% FBS simulates normal (non-stressed) conditions, while $2.5 \%$ and $1 \%$ FBS conditions simulate a stressed environment on the MRC-5 lung cells by depriving the cells of nutrients available to them. The data indicates a similar level of decreased proliferation regardless of stress conditions placed on the cells.

Assessment of the MRC-5 and WI-38 lung cell lines for apoptotic activity (Fig. 2) suggests that apoptosis is occurring at higher than baseline levels in MRC-5 and WI-38 cells exposed to 250 and 25 ppm WTC dust.

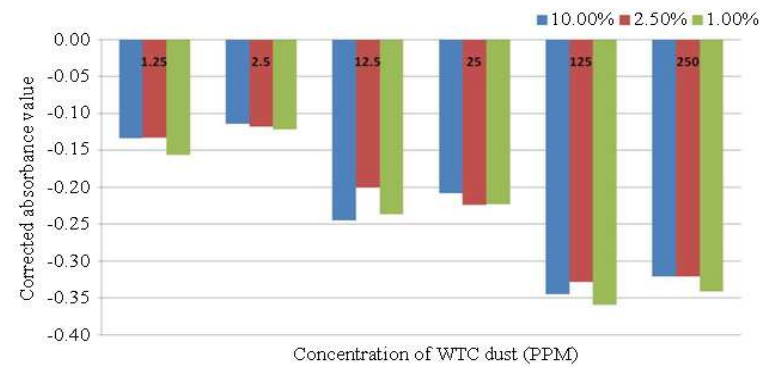

Fig. 1: Corrected absorbances of WTC dust treated cells

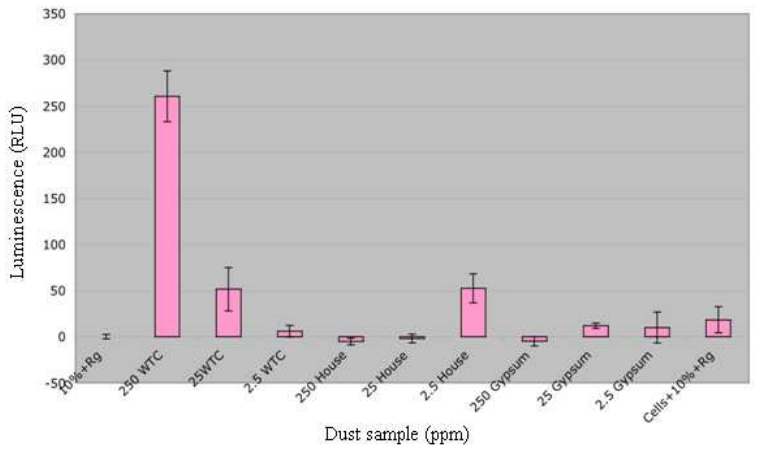

(b)

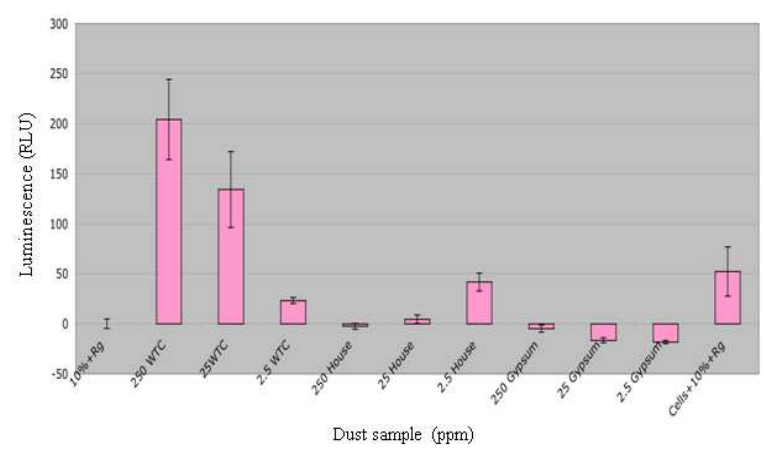

(d)

Fig. 2: (a) MRC-5 apoptosis assessment; (b) WI-38 apoptosis assessment; (c) MRC-5 apoptosis assessment (1.5 h reading); (d) WI-38 apoptosis assessment ( $1.5 \mathrm{~h}$ reading) 


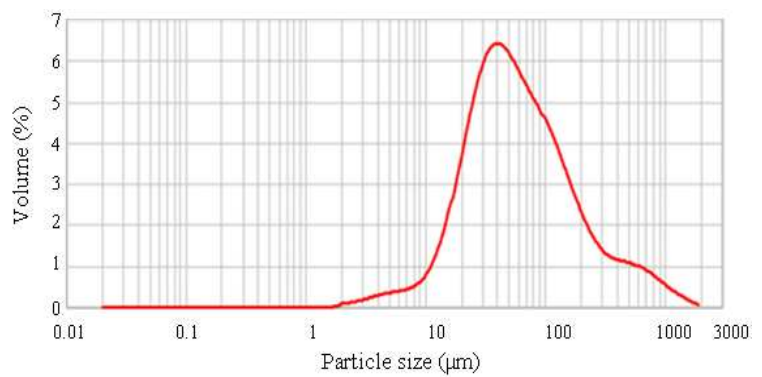

(a)

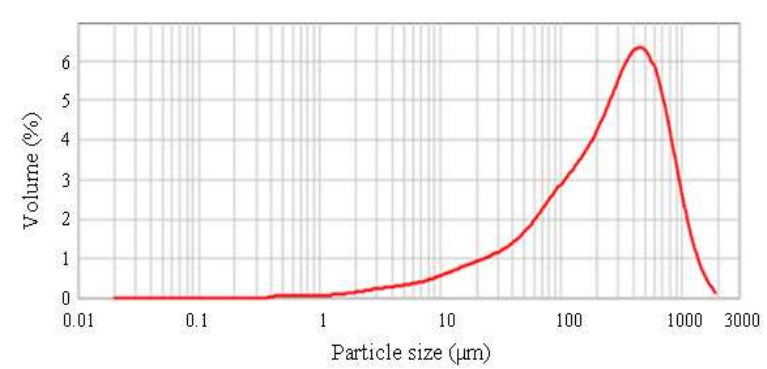

(b)

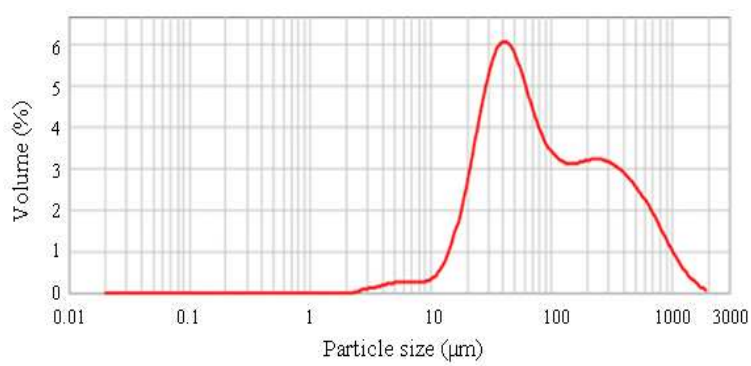

(c)

Fig. 3: Particle size distribution. (a) Household dust; (b) gypsum; (c) world trade center dust

WI-38 human lung fibroblast cells were used in the assessment to further validate the preliminary findings of the MRC-5 human lung fibroblast cells. It should be emphasized that at $25 \mathrm{ppm}$ WTC dust, decreased proliferation and increased apoptosis presented in the MRC-5 cells, suggesting a correlation. The decrease in proliferation as well as an increase in apoptotic activity of the lung cells following exposure to WTC dust provides evidence towards the possibility of having WTC dust classified as a mutagenic substance.

The analysis is shown in Fig. 3, which shows that all three samples contained particles ranging in size from $10-1000 \mu \mathrm{m}$ in size. The WTC dust reading shows one large peak between 10 and $100 \mu \mathrm{m}$, with a smaller peak between 100 and $1000 \mu \mathrm{m}$. This indicates that the majority of particles in this sample were between 10 and $100 \mu \mathrm{m}$ in size, with a smaller, but still significant portion of the sample ranging from $100-1000 \mu \mathrm{m}$ in size. The majority of particles in the household dust sample ranged from $10-100 \mu \mathrm{m}$ in size with a smaller amount of particles ranging between 100 and $1000 \mu \mathrm{m}$ in size. The majority of particles in the gypsum sample ranged from $100-1000 \mu \mathrm{m}$ in size. This particle size analysis shows that, for all 3 substances, the particle size range was primarily between 10 and $1000 \mu \mathrm{m}$. Since the household dust and gypsum samples fall within the same particle size distributions as the WTC dust, they can be used as size controls. Therefore, particle size can be ruled out as a contributing factor for any difference in apoptosis and proliferation in cells. Equal size range indicates that the effects of the substances on the cells are a result of the chemical composition of each test media and not the result of particle size related issues stemming from physical contact.

\section{CONCLUSION}

In summary, the results indicate that low doses of this contaminant have an effect on cell viability and stimulate an increase in apoptosis levels as well. This data correlates with the lung damage that is now linked to rescuers that worked at the WTC site following the tragedy. Lead, cadmium, zinc and mercury are some of the heavy metals known to be present in WTC dust. In future experiments, the mutagenic properties of these heavy metals should also be compared to WTC dust.

\section{ACKNOWLEDGEMENT}

We express our appreciation to Lioy ${ }^{[9]}$ of Rutgers University for providing us with a sample of World Trade Center dust, Dr. Goldberg, Dr. Sickierka and Mr. Kevin Olson of the Department of Chemistry and Biochemistry of Montclair State University for providing us with equipment used throughout our experiments. We also thank Dr. Sandra Passchier of the Department of Earth and Environmental Science of 
Montclair State University who assisted with the particle size analysis. Partial funding for this project was provided from NSF Award \#0638708, the NIH MARC Program at Montclair State University and the Bonnie Lustigman Research Fellowship at Montclair State University.

\section{REFERENCES}

1. El-Zein, R.A., M.B. Schabath, C.J. Etzel, M.S. Lopez, J.D. Franklin and M.R. Spitz, 2006. Cytokinesis-blocked micronucleus assay as a novel biomarker for lung cancer risk. Cancer Res., 66: 6449-6456. PMID: 16778224.

2. Fatur, T., T.T. Lah and M. Filipic, 2003. Cadmium inhibits repair of UV-, methyl methanesulfonateand N-methyl-N-nitrosourea-induced DNA damage in Chinese hamster ovary cells. Fundam. Mol. Mechan. Mutagenes., 529: 109-116. PMID: 12943924.

3. Greenberger, P.A., 2008. Immunologic lung disease. J. Allerg. Clin. Immunol., 121: S393-S397. PMID: 18241689.

4. Hart, K., A. Haugen and S. Zienolddiny, 2008. Allele-specific induction of IL1B-31T/C promoter polymorphism by lung carcinogens. Mutat. Res., 656: 14-18. PMID: 18656550.

5. Klein-Szanto, A.J.P., M. Terzaghi, L.D. Mirkin, D. Martin and M. Shiba, 1982. Propagation of normal human epithelial cell populations using an in vivo culture system: Description and applications. Am. J. Pathol., 108: 231-239. PMID: 6821529.

6. Lee, H.J., H.J. Lee, E.O. Lee, S.G. Ko, H.S. Bae and C.H. Kim et al., 2008. Mitochondriacytochrome C-caspase-9 cascade mediates isorhamnetin-induced apoptosis. Cancer Lett., 270: 342-353. PMID: 18617322.
7. Leung, H.W.C., M.J. Hour, W.T. Chang, Y.C. Wu and M.Y. Lai et al., 2008. P38-associated pathway involvement in apoptosis induced by photodynamic therapy with Lonicera japonica in human lung squamous carcinoma CH27 cells. Food Chem. Toxicol., 46: 3389-3400. PMID: 18796326.

8. Lin, S.S., H.P. Huang, J.S. Yang, J.Y. Wu and T.C. Hsai et al., 2008. DNA damage and endoplasmic reticulum stress mediated curcumininduced cell cycle arrest and apoptosis in human lung carcinoma A-549 cells through the activation Caspases cascade- and mitochondrial-dependent pathway. Cancer Lett., 272: 77-90. PMID: 18701210.

9. Lioy, P.J., C.P. Weisel, J.R. Millette, S. Eisenreich and D. Vallero et al., 2002. Characterization of the dust/smoke aerosol that settled east of the World Trade Center (WTC) in lower Manhattan after the collapse of the WTC 11 September 2001. Environ. Health Perspect., 110: 703-714. PMID: 12117648.

10. McEntee, J.C. and Y. Ogneva-Himmelberger, 2008 Diesel particulate matter, lung cancer and asthma incidences along major traffic corridors in MA, USA: A GIS analysis. Health Place, 14: 817-828. PMID: 18280198.

11. Wesselkamper, S.C., L.M. Case, L.N. Henning and M.T. Borchers et al., 2005. Gene expression changes during the development of acute lung injury: role of transforming growth factor beta. Am. J. Respiratory Crit. Care Med., 172: 1399-1411. PMID: 16100012. 